\title{
Determining the Influence of Various Cutting Parameters on Surface Roughness during Wet CNC Turning Of AISI 1040 Medium Carbon Steel.
}

\author{
Yacov sahijpaul ${ }_{\text {(Research scholar, U.C.O.E. PUNJABI UNIVERSITY, INDIA)I }}{ }^{2}$ \\ (Assistant professor, U.C.O.E. PUNJABI UNIVERSITY, INDIA)2
}

\begin{abstract}
The purpose of this experimental investigation was to analyse the effect of controlled cutting parameters namely cutting speed, feed rate, depth of cut, cutting fluid concentration and two cutting fluids with different base oils on surface roughness $\left(R_{a}\right)$ of EN8 or AISI 1040 steel during turning operation by applying design of experiments, custom design method, analysis of variance, leverage plots and desirability profiling using JMP software to optimize surface roughness during wet CNC turning operation. The analysis reveals that feed rate has the most significant effect on surface roughness $\left(R_{a)}\right.$ and value of surface roughness does not significantly differ for two different cutting fluids used.
\end{abstract}

Keywords: CNC turning, custom design, jmp, regression, surface roughness.

\section{Introduction}

Turning is the primary operation in most of the production process in the industry, surface finish of turned components has a great influence on quality of the product [1]. In machining of parts, surface quality is one of the most specific customer requirements where major indication of surface quality on machined parts is surface roughness value [2]. The performance and service life of the machined component are often affected by its surface finish, nature and extent of residual stresses and presence of surface or sub-surface micro cracks, particularly when that component is to be used under dynamic loading or in conjugation with some other mating parts [3]. Surface roughness also determines how a real object interacts with its environment. Rough surfaces usually wear more quickly and have high frictional coefficient than smooth surfaces, roughness is a good predictor of performance of mechanical components, since irregularities in the surface may form nucleation sites for cracks and corrosion, although roughness is undesirable it is complex and expensive to control in manufacturing [4]. In turning process parameters such as cutting speed, feed rate, depth of cut, tool geometry and material, use of cutting fluids impact the material removal rate and surface roughness [5]. The three primary input control parameters in turning operation are cutting speed, feed rate and depth of cut [6]. Where cutting speed is the relative velocity between cutting tool and the surface of the work piece it is operating on, Feed rate is the relative velocity at which the cutter is advanced along the work piece, its vector is perpendicular to the vector of cutting speed [7]. Depth of cut is the thickness of the material that can be removed by one pass of cutting tool over the work piece [6]. EN8 or 080M40 is unalloyed medium carbon steel which has medium strength and good tensile strength; it is suitable for manufacture of shafts, studs, keys, general purpose axles etc [8]. Many researchers have tried to optimize surface roughness for different materials by varying machining parameters and by implying different methods for designing the experiments and analysing the results. Yang and Tarng (1998) [9] used taguchi method to investigate the cutting characteristics of S4SC steel bars using tungsten carbide tools for optimizing the tool life and surface roughness during turning. Kopak J. et al. (2002) [10] used signal to noise ratio to achieve the optimal surface roughness during fine turning of cold pre-formed steel workpieces. Davim (2003) [11] used taguchi technique to study the influence of cutting velocity, feed rate and cutting time during turning of material matrix composites (MMC). Kirby (2006) [12] investigated the use of taguchi parameter design for optimizing surface roughness generated by a CNC turning operation while turning aluminium alloy 6061-T6511 the study utilizes a standard orthogonal array for determining the optimum turning parameters with an applied noise factor of spindle vibrations due to damaged jaw and found out that feed rate had highest effect on surface roughness and noise factor showed statistically insignificant effect. Thamizhmanii et al. (2007) [13] analysed the effect of machining parameters, speed, feed rate, depth of cut on surface roughness using taguchi method utilizing L18 orthogonal array while turning soft SCM 440 steel to find out that depth of cut had most significant effect in producing lower surface roughness. Though many research's have been carried out on the effect of varying levels of primary cutting parameters like cutting speed, feed rate and depth of cut on surface roughness, tool wear rate and material removal rate like [13], [14] etc. Korat et al. (2012) [15] analysed the effects of nose radius, cutting environment (dry and wet) along with primary cutting factors. H. Singh et al. ( 2011) [16] during dry turning of EN8 investigated the effect of cutting parameters of 
cutting speed, feed rate and depth of cut using ordinary lathe deducing that the spindle speed (the most significant factor) contributed $63.90 \%$, depth of cut (second most significant factor) contributed only $11.32 \%$ and feed rate contribution was least with $8.33 \%$ for Ra. The contribution for feed and RPM was $60.91 \%$ and $29.83 \%$.whereas the depth of cut contributed only $7.82 \%$ for material removal rate, whereas D. Singh et al. (2012) [17] also during dry turning of EN 8 on CNC lathe concluded that speed and depth of cut had negligible effect on the surface roughness and feed rate for surface roughness shows increasing trend. In dry cutting operations, the friction and adhesion between chip and tool is high resulting in high temperatures and wear rates, so complete dry cutting is not recommended and cutting fluid is also needed to remove the chips from chip tool interface thus preventing it to stick to tool [18].Though new techniques of minimum quantity lubrication (MQL), cryogenic cooling have evolved for cooling of tool and workpiece during machining but still flood cooling continues to be used as these use some different equipments than regular and in these methods cutting fluid could not be reused but in flood cooling technique the fluid is filtered and reused., In our experiment we intent to pay attention on the effects produced by primary cutting parameters of cutting speed, feed rate and depth of cut along with changing cutting fluid concentration and cutting fluid types on surface roughness and chip tool interface temperature while wet turning EN 8 steel on a CNC lathe machine since no thorough research work has been carried out on this material during wet CNC turning utilizing this set of parameters, levels and statistical methods. Since the advent of $\mathrm{CNC}$ it has become unusual to use non computerized tool path control for the purpose of turning in a manufacturing industry as CNC increases the productivity and profit for manufacturing industry because of its ability to finish a job in minimum time. D.O.E custom design along with other statistical tools have been used in the experiment to achieve the objective of optimal surface roughness during wet CNC turning of EN8 medium carbon steel. Two cutting fluids with different base oils have been used in order to make the design robust to such variations. JMP version 10.0.2 software has been employed to study the significance of the cutting parameters using leverage plots and confirming their authenticity through analysis of variance. Desirability profiling using minimum response goal as objective in prediction profiler was performed to get optimum surface roughness.

\section{Experimental detail}

2.1 Material of the workpiece and CNC specifications - EN8 is a medium carbon steel it has good tensile strength and is suitable for manufacture of shafts, studs, keys etc. The round bars of diameter $32 \mathrm{~mm}$ and length $200 \mathrm{~mm}$ were used. The $20 \mu \mathrm{m}$ of the outer corroded layer was removed and turning was carried up to length of $160 \mathrm{~mm}$.

TABLE 1. Chemical composition of EN 8.

\begin{tabular}{|c|c|c|c|c|}
\hline $\mathrm{C} \%$ & $\mathrm{Si} \%$ & $\mathrm{Mn} \%$ & $\mathrm{~S} \%$ & $\mathrm{P} \%$ \\
\hline $\mathbf{0 . 3 5 / 0 . 4 5}$ & $\mathbf{0 . 0 5 / 0 . 3 5}$ & $\mathbf{0 . 6 0 / 0 . 1 0}$ & $\mathbf{0 . 0 6} \max$ & $\mathbf{0 . 0 6} \max$ \\
\hline
\end{tabular}

TABLE 2. CNC lathe specifications and cooling environment.

\begin{tabular}{|c|c|}
\hline Model & LOKESH TL 30 XL \\
\hline Power & $11 \mathrm{hp} / 8.2 \mathrm{KW}$ \\
\hline controller & FANUC Series 0 i TC \\
\hline Max. Spindle speed & $3000 \mathrm{RPM}$ \\
\hline Chuck size & $249.6 \mathrm{~mm}$ \\
\hline Spindle size & $\mathrm{A}_{2} 6$ \\
\hline Tool holder & Standard Lokesh made with $25^{*} 25 \mathrm{~mm}$ shank. \\
\hline Environment & Wet (flood cooling) \\
\hline
\end{tabular}

2.2.2. Cutting tool - The cutting tool used was Sandwik Coromant made carbide turning insert, CNMG 431-PF 4225 which was considered taking care of workpiece material and cutting conditions.

TABLE 3. Specifications of the cutting tool insert.

\begin{tabular}{|c|c|}
\hline Insert thickness & 0.1875 inches. \\
\hline Nose radius & 0.0157 inches \\
\hline \multirow{2}{*}{ ISO number } & CNMG 12 04 04-PF \\
& 4225 \\
\hline No. of edges & 4 \\
\hline
\end{tabular}


2.2.3 Cutting fluids - The two types of cutting fluids were specially prepared by Nirmal industries, phase 1, Chandigarh.

A. Cool-cut-Nirma $40 \mathrm{~A}$-water soluble cutting oil using spindle oil as base oil.

B. Cool-cut-Nirma $30 \mathrm{~A}$ - water soluble cutting oil using heavy duty diesel oil as base oil.

\subsection{Measuring Instruments}

2.3.1 Refractometer (Concentration measurement) - It is an instrument used for measuring the refractive index which corresponds to the concentration of the fluid on the other scale. The refractometer used was ERMA Japanese made having a range of $0-50 \%$ portable hand refractometer.

3.3.2 Infrared thermometer (Temperature measurement) - To measure the chip-tool interface temperature digital infrared thermometer MEXTECH DT-8812 having a range between $-50^{\circ} \mathrm{C}$ to $550^{\circ} \mathrm{C}$ with a spectral response of $6-14 \mu \mathrm{m}$.

3.3.3 Surface roughness analyzer - The instrument used for measuring surface roughness was SJ-201 Mitutoyo made, specifications of which are given in table 4 .

Table 4. Specifications of surface roughness analyzer.

\begin{tabular}{|l|l|}
\hline Measuring range & $-200 \mu \mathrm{m}$ to $150 \mu \mathrm{m}$ \\
\hline Stylus material & Diamond \\
\hline Stylus tip radius & $5 \mu \mathrm{m}$ \\
\hline Measuring force & $4 \mathrm{mN}$ \\
\hline Evaluation length & $12.5 \mathrm{~mm}$ \\
\hline
\end{tabular}

\subsection{EXPERIMENTAL DESIGN}

To increase the effectiveness of the design, for achieving objective in best possible time and taking care of economical constraints JMP Custom design (by default) approach was used according to process parameters and their levels.

TABLE 5. Factors, levels and degree of freedom.

\begin{tabular}{|c|c|c|c|c|}
\hline S.NO & CONTROL FACTOR & No. of levels & Degree of freedom & $\begin{array}{c}\text { Values at different } \\
\text { levels }\end{array}$ \\
\hline 1. & Cutting speed $(\mathrm{rpm})$ & 2 & 1 & $\mathrm{~L}_{1}=1000, \mathrm{~L}_{2}=2000$ \\
\hline 2. & Feed rate $(\mathrm{mm} / \mathrm{rev})$ & 2 & 1 & $\mathrm{~L}_{1}=0.125, \mathrm{~L}_{2}=0.250$ \\
\hline 3. & Depth of cut $(\mathrm{mm})$ & 2 & 1 & $\mathrm{~L}_{1}=1, \mathrm{~L}_{2}=0.5$ \\
\hline 4. & Cutting fluid concentration $(\%)$ & 4 & 3 & $\begin{array}{c}\mathrm{L}_{1}=2, \mathrm{~L}_{2}=4, \mathrm{~L}_{3}=8, \\
\mathrm{~L}_{4}=12\end{array}$ \\
\hline
\end{tabular}

2.4.1 Customized experimental design - The customized experimental design was prepared using a controlled factor design and nuisance factor blocking which consists of two different types of cutting fluids and each having one level denoted by $F_{1}$ and $F_{2}$ in the table, so as to compare the cutting fluids performances thoroughly with regard to temperatures and surface roughness responses while machining of EN 8 and to make the process robust.

TABLE 6. Customized design for the experiment

\begin{tabular}{|c|c|c|c|c|c|c|}
\hline \multicolumn{5}{|c|}{ CONTROLLED FACTOR DESIGN } & \multicolumn{2}{c|}{$\begin{array}{c}\text { NUISANCE FACTOR } \\
\text { BLOCKING }\end{array}$} \\
\hline RUN & D.O.C & CONC. & SPEED & FEED & $\begin{array}{c}\text { FLUID 1 } \\
40 ~ A\end{array}$ & $\begin{array}{c}\text { FLUID 2 } \\
30 A\end{array}$ \\
\hline 1 & $\mathrm{~L}_{2}$ & $\mathrm{~L}_{2}$ & $\mathrm{~L}_{1}$ & $\mathrm{~L}_{1}$ & $\mathrm{~F}_{1}$ & $\mathrm{~F}_{2}$ \\
\hline 2 & $\mathrm{~L}_{1}$ & $\mathrm{~L}_{3}$ & $\mathrm{~L}_{1}$ & $\mathrm{~L}_{2}$ & $\mathrm{~F}_{1}$ & $\mathrm{~F}_{2}$ \\
\hline 3 & $\mathrm{~L}_{1}$ & $\mathrm{~L}_{1}$ & $\mathrm{~L}_{1}$ & $\mathrm{~L}_{1}$ & $\mathrm{~F}_{1}$ & $\mathrm{~F}_{2}$ \\
\hline 4 & $\mathrm{~L}_{2}$ & $\mathrm{~L}_{1}$ & $\mathrm{~L}_{2}$ & $\mathrm{~L}_{2}$ & $\mathrm{~F}_{1}$ & $\mathrm{~F}_{2}$ \\
\hline 5 & $\mathrm{~L}_{1}$ & $\mathrm{~L}_{4}$ & $\mathrm{~L}_{2}$ & $\mathrm{~L}_{1}$ & $\mathrm{~F}_{1}$ & $\mathrm{~F}_{2}$ \\
\hline 6 & $\mathrm{~L}_{1}$ & $\mathrm{~L}_{2}$ & $\mathrm{~L}_{2}$ & $\mathrm{~L}_{2}$ & $\mathrm{~F}_{1}$ & $\mathrm{~F}_{2}$ \\
\hline 7 & $\mathrm{~L}_{2}$ & $\mathrm{~L}_{4}$ & $\mathrm{~L}_{1}$ & $\mathrm{~L}_{2}$ & $\mathrm{~F}_{1}$ & $\mathrm{~F}_{2}$ \\
\hline 8 & $\mathrm{~L}_{2}$ & $\mathrm{~L}_{3}$ & $\mathrm{~L}_{2}$ & $\mathrm{~L}_{1}$ & $\mathrm{~F}_{1}$ & $\mathrm{~F}_{2}$ \\
\hline
\end{tabular}


Table 7. Results of surface roughness response for turning operation.

\begin{tabular}{|c|c|c|c|c|c|c|c|c|c|}
\hline \multicolumn{5}{|c|}{$\begin{array}{c}\text { REPLICATIONS CUTTING FLUID } 1 \\
40 \mathrm{~A}(\mu \mathrm{m})\end{array}$} & \multicolumn{4}{|c|}{$\begin{array}{c}\text { REPLICATIONS CUTTING FLUID } 2 \\
30 \mathrm{~A}(\mu \mathrm{m})\end{array}$} & \multirow{2}{*}{$\begin{array}{c}\mathrm{R}_{\mathrm{a}} \\
\text { AVERAGE }\end{array}$} \\
\hline RUN & $\mathrm{R}_{1}$ & $\mathrm{R}_{2}$ & $\mathrm{R}_{3}$ & $\mathrm{R}_{4}$ & $\mathrm{R}_{5}$ & $\mathrm{R}_{6}$ & $\mathrm{R}_{7}$ & $\mathrm{R}_{8}$ & \\
\hline 1 & 2.07 & 2.11 & 2.33 & 2.21 & 2.71 & 2.73 & 2.60 & 2.63 & 2.4238 \\
\hline 2 & 2.90 & 3.03 & 2.94 & 3.15 & 3.80 & 3.77 & 3.39 & 3.64 & 3.3275 \\
\hline 3 & 1.68 & 1.84 & 1.83 & 1.93 & 2.46 & 2.24 & 2.48 & 1.95 & 2.0513 \\
\hline 4 & 2.69 & 2.69 & 2.68 & 2.66 & 2.46 & 2.72 & 2.75 & 2.71 & 2.6700 \\
\hline 5 & 2.53 & 2.45 & 2.53 & 2.49 & 2.87 & 2.53 & 2.66 & 2.60 & 2.5825 \\
\hline 6 & 3.02 & 3.28 & 3.32 & 3.19 & 3.60 & 3.57 & 3.52 & 3.55 & 3.3813 \\
\hline 7 & 2.95 & 2.81 & 3.12 & 2.72 & 3.39 & 3.09 & 3.58 & 3.00 & 3.0825 \\
\hline 8 & 2.52 & 2.50 & 2.45 & 2.48 & 2.79 & 2.68 & 2.81 & 2.77 & 2.6250 \\
\hline
\end{tabular}

\subsection{Data collection}

\section{Data Analysis and Results}

In accordance with the customized array a total of 16 samples were turned and replications were made four times each for two extraneous conditions of different base cutting fluids by running the stylus perpendicular to the lay surface for each turned piece to reduce the measurement errors which could lead to variability. If a full factorial design may have been employed to this experiment the number of runs would have increased from sixteen to sixty four. Therefore we are able to save both time and material during experimental run which is an important part of industrial experimentation. Temperature readings were also taken at the workpiece tool interference points. Careful preparation of the cutting fluid and water mixture were carried out using measuring beaker and refractometer to check the concentration of the cutting fluid in the mineral water to prevent foaming. Experiments were carried out at a room temperature of $20^{\circ} \mathrm{C}$ approximately. The data processing has been carried out using JMP version 10.0.2 statistical software utilizing custom design, fit design features which includes leverage plots, prediction profiler and surface profiler. The comparison between two cutting fluids with different base oils was also made using two sample t tests taking temperature and surface roughness as response factors. Analysis of variance was applied to provide the statistical values of the parameter affecting the response by looking at the F ratios.

\subsection{Regression reports}

These provide information about model fit, effect significance and model parameters, which in case of our deduction of results include leverage plots, analysis of variance and summary of fit, along with these we have shown desirability plots to find out the level of parameters that lead to optimal surface roughness.

\subsubsection{Leverage plots}

In case of general linear hypotheses both significance and collinearity is seen through graphical tool called leverage plots. They were introduced by Sall (1990) as extension of the partial regression residual plots of Besley, Kuh and Welsh (1980) (Freund et al.) 2003 [19]. A leverage plot is defined as a horizontal line drawn to represent the model fit constrained by hypotheses of interest. A slanted line is drawn to represent the fitted model without constraint. Each observation is positioned as a point in plot such that vertical distance from that point to slanted line of fit is the unconstrained residual and the distance from the point to horizontal line is the residual constrained by hypotheses. The leverage plot is same as a simple plot of the data with the mean and regression lines (John Sall 1990) [20].

Suppose that the estimable hypothesis of interest is $L \beta=0$, The leverage plot characterizes this test by plotting points so that the distance of each point to the sloped regression line displays the unconstrained residual, and the distance to the $x$-axis displays the residual when the fit is constrained by the hypothesis. the difference between the sums of squares of these two groups of residuals is the sum of squares due to the hypothesis, which becomes the main ingredient of the F test.

The parameter estimates constrained by the hypothesis are given as by [20], [21].

$\mathrm{b}_{0}=\mathrm{b}-\left(\mathrm{X}^{\prime} \mathrm{X}\right)^{-1} \mathrm{~L}^{\prime} \lambda$, where $\mathrm{b}$ is the least squares estimate

$\mathrm{b}=\left(\mathrm{X}^{\prime} \mathrm{X}\right)^{-1} \mathrm{X}^{\prime} \mathrm{y}$ and $\left.\lambda=\left(\mathrm{L}\left(\mathrm{X}^{\prime} \mathrm{X}\right)^{-1} \mathrm{~L}^{\prime}\right)^{-1} \mathrm{Lb}\right)$

Compare the residuals for the unconstrained and hypothesis-constrained residuals, respectively. 


$$
\begin{aligned}
r & =y-X b \\
r_{0} & =r+X\left(X^{\prime} X\right)^{-1} L^{\prime} \lambda \\
v_{x} & =X\left(X^{\prime} X\right)^{-1} L^{\prime} \lambda \\
v_{y} & =r+v_{x}
\end{aligned}
$$

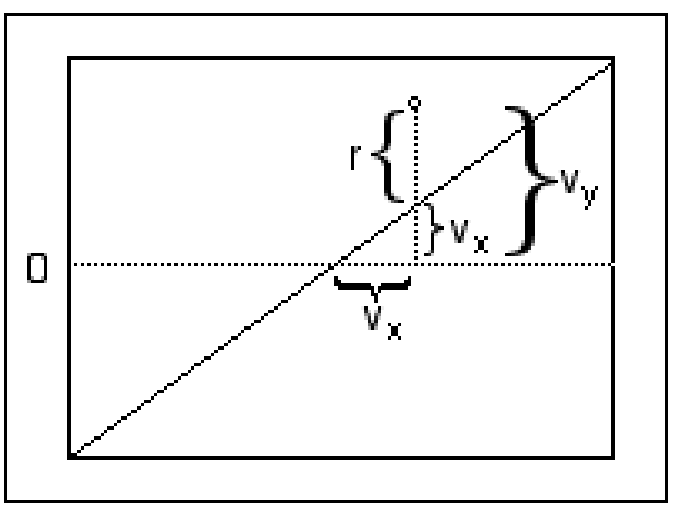

Fig.1Construction of a leverage plot.

To get a leverage plot, the $x$-axis values $\mathbf{v}_{\mathrm{x}}$ of the points are the differences in the residuals due to the hypothesis, so that the distance from the line of fit (with slope 1) to the $x$-axis is this difference. The $y$-axis values $\mathbf{v}_{\mathrm{y}}$ are just the $x$-axis values plus the residuals under the full model.

\subsubsection{Superimposing a test on the Leverage Plot}

In simple linear regression, you can plot the confidence limits for the expected value as a smooth function of the regressor variable $\mathrm{x}$

$\operatorname{Upper}(\mathrm{x})=$

$$
\mathrm{xb}+t_{\alpha / 2} \sqrt{\mathrm{x}\left(\mathrm{X}^{\prime} \mathrm{X}\right)^{-1} \mathrm{x}^{\prime}}
$$

Lower $(\mathrm{x})=$

$$
\mathrm{xb}-t_{\alpha / 2} \sqrt{\mathrm{x}\left(\mathrm{X}^{\prime} \mathrm{X}\right)^{-1} \mathrm{x}^{\prime}}
$$

Where, $\mathbf{x}=[1 x]$ is the 2-vector of regressors.

This hyperbola is a useful significance-measuring instrument. (JMP SUPPORT)

$>$ If the slope parameter is significantly different from zero, the confidence curve will cross the horizontal line of the response mean.

$>$ If the slope parameter is not significantly different from zero, the confidence curve will not cross the horizontal line of the response mean.

$>$ If the t-test for the slope parameter is sitting right on the margin of significance, the confidence curve will have the horizontal line of the response mean as an asymptote

\section{Significant}

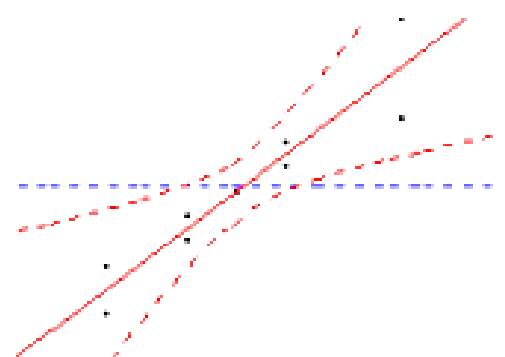

confidence curve

crosses horizontal line
Borderline

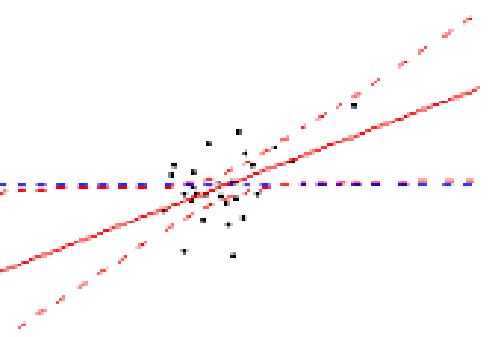

confidence curve

asymptotic to horizontal line
Not Significant

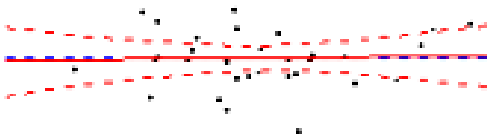

confidence curve

does not cross

horizontal line

Fig. 2 Cases of Significant, Borderline, and non significant Confidence Curves. 
3.2.3 Leverage plots and LS mean plots for speed, feed, concentration of fluid and depth of cut versus surface roughness.

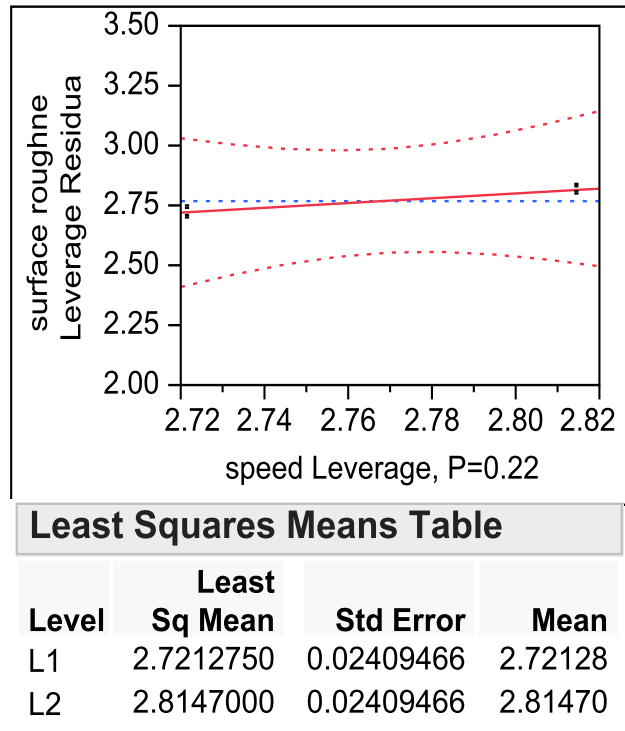

\section{LS Means Plot}
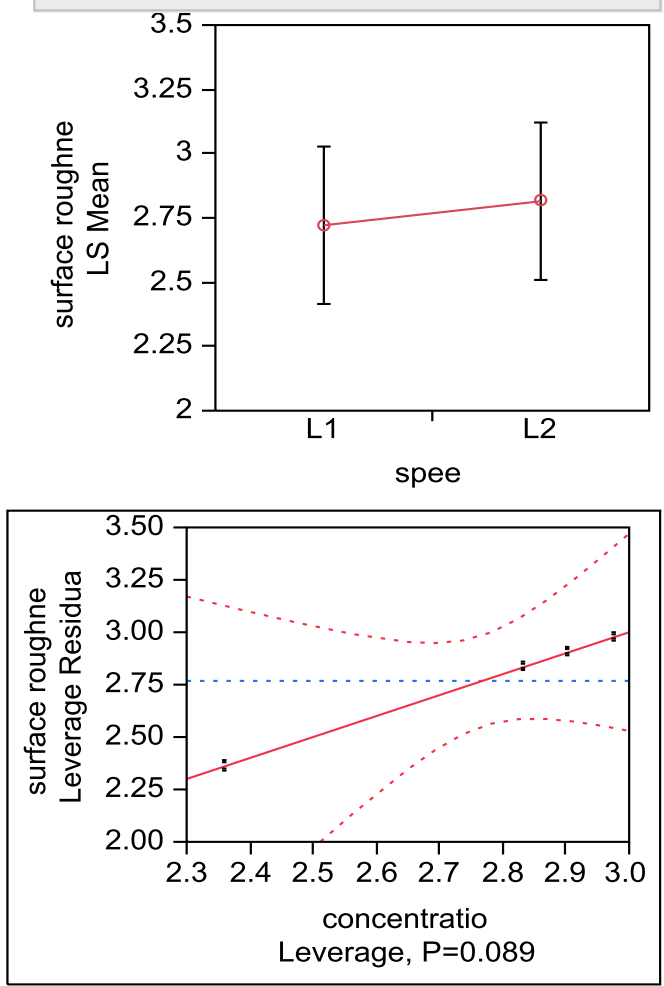

Least Squares Means Table

$\begin{array}{lrrr} & \text { Least } & & \\ \text { Level } & \text { Sq Mean } & \text { Std Error } & \text { Mean } \\ \text { L1 } & 2.3606500 & 0.03407500 & 2.36065 \\ \text { L2 } & 2.9025500 & 0.03407500 & 2.90255 \\ \text { L3 } & 2.9762500 & 0.03407500 & 2.97625 \\ \text { L4 } & 2.8325000 & 0.03407500 & 2.83250\end{array}$
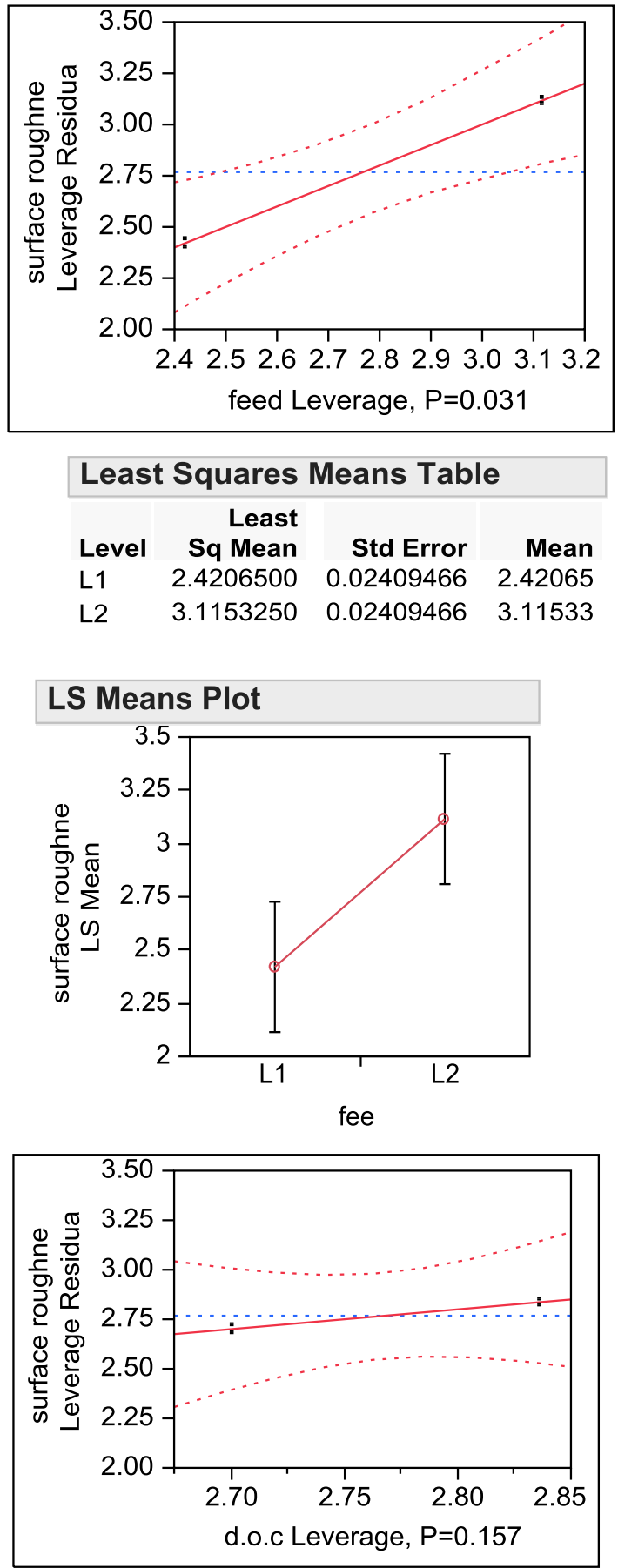

\section{Least Squares Means Table}

Least

Level Sq Mean Std Error Mean

L1 $\quad 2.8356500 \quad 0.02409466 \quad 2.83565$

L2 $\quad 2.7003250 \quad 0.02409466 \quad 2.70033$ 

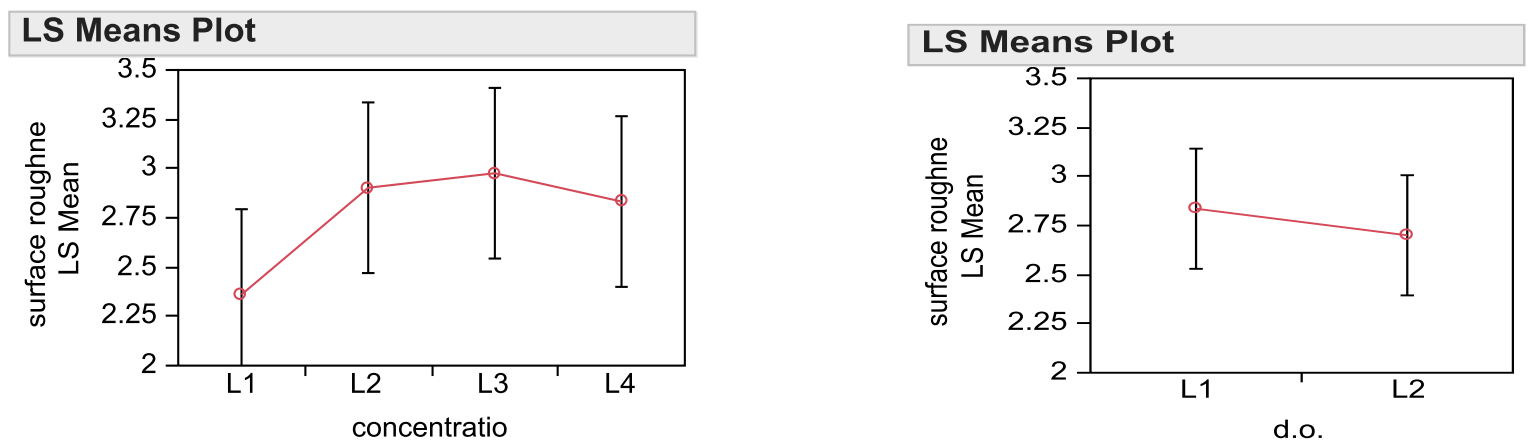

The above results suggest that feed is the only significant factor which affects the surface roughness.

\subsubsection{Summary of fit}

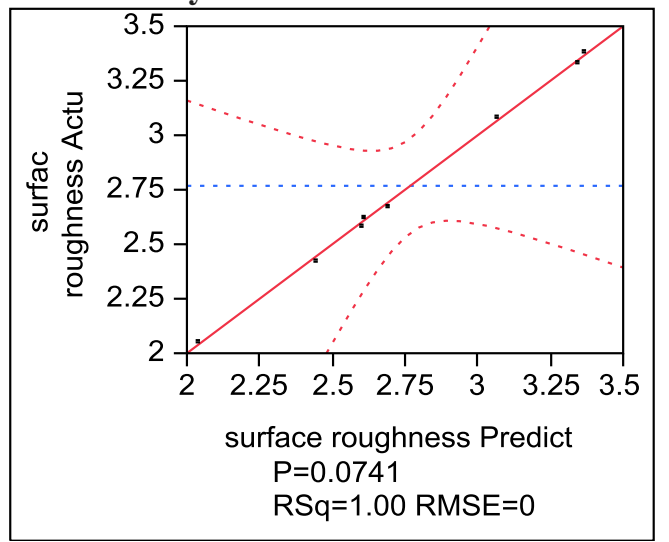

\begin{tabular}{|lr|}
\hline Summary of Fit & \\
\hline RSquare & 0.998436 \\
RSquare Adj & 0.989051 \\
Root Mean Square Error & 0.048189 \\
Mean of Response & 2.767988 \\
Observations (or Sum Wgts) & 8
\end{tabular}

The RSquare value close to 1 indicates a better fit. A response close to overall response mean.

3.2.5 Analysis of variance.

\section{ANOVA TABLE}

$\begin{array}{lrrrc}\text { Source } & \text { DF } & \begin{array}{r}\text { Sum of } \\ \text { Squares }\end{array} & \text { F Ratio } & \text { Prob > F } \\ \text { d.o.c } & 1 & 0.03662571 & 15.7719 & 0.1570 \\ \text { concentration } & 3 & 0.46313207 & 66.4786 & 0.0899 \\ \text { speed } & 1 & 0.01745646 & 7.5172 & 0.2226 \\ \text { feed } & 1 & 0.96514671 & 415.6154 & 0.0312^{*}\end{array}$

To confirm the significance of feed that we found out from leverage plots ANOVA test was performed which gave the result that feed was a significant factor affecting the surface roughness at $\alpha=.05$ level of significance.

3.2.6 Cube plots and desirability plots using prediction profiler. feed $=\mathrm{L} 1$

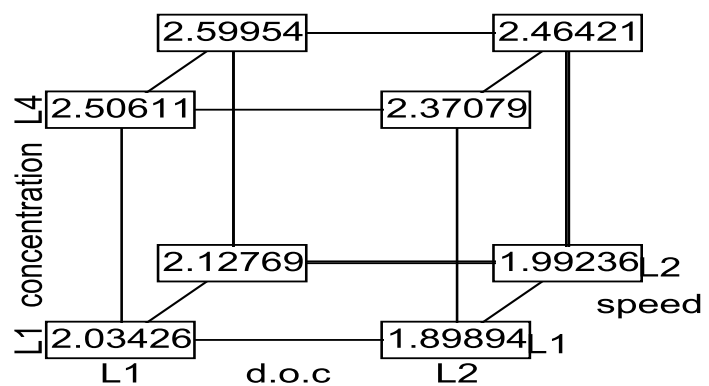

feed $=$ L2

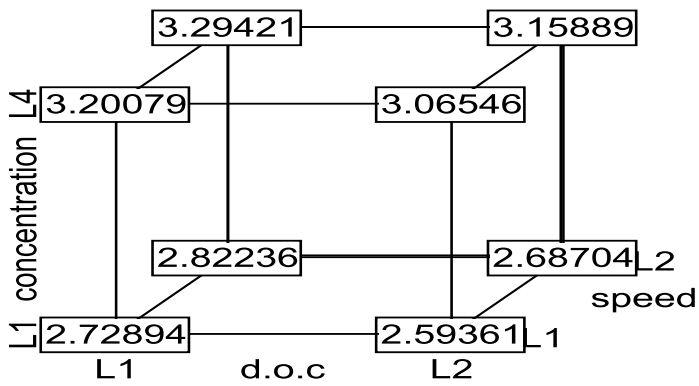

Fig. 3 Cube plots. 
To find out the optimal parameters for surface roughness we plot the cube plots and found out that at constant feed levels L1 and L2. The parameter feed at L1, speed at L1, depth of cut L2 and cutting fluid concentration of $1.89894 \mu \mathrm{m}$. To confirm the credibility of the cube plot we use prediction profiler. Prediction profiles are especially useful in multiple-response models to help judge which factor values can optimize a complex set of criteria.
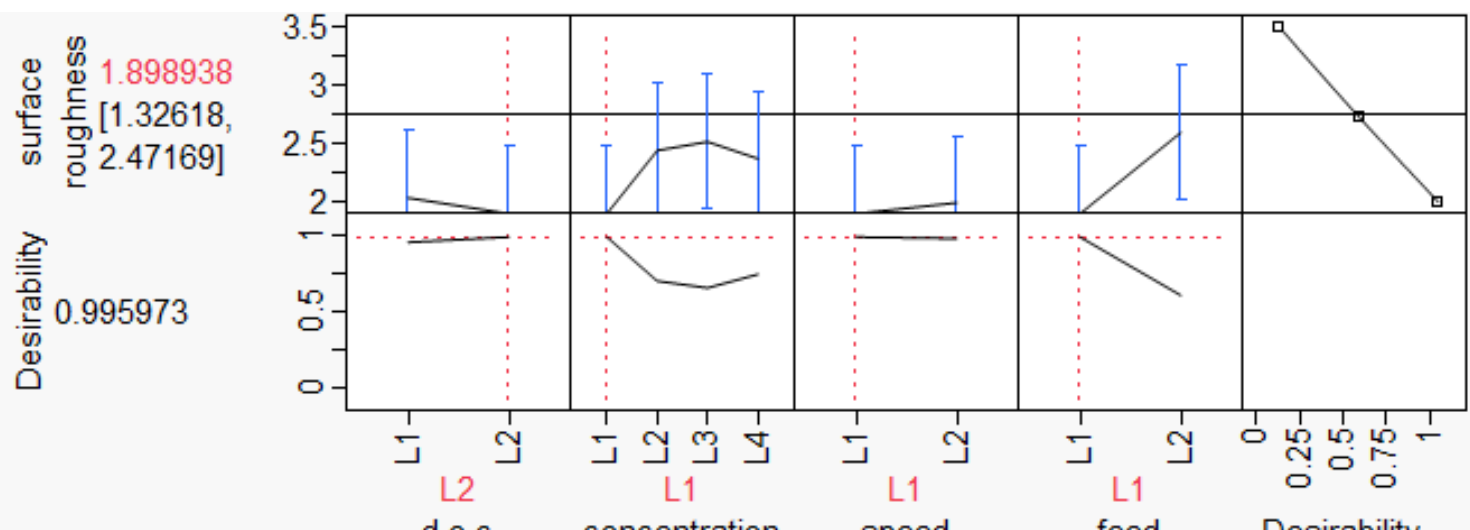

d.o.c concentration speed
Fig.4 Desirability plots using prediction profiler.

The desirability plots were drawn keeping the response goal as minimum and reaching the same result for optimum level of surface roughness with a desirability of .995973.

\subsubsection{Comparison between cutting fluids.}

Surface roughness and cooling characteristics of cutting fluids were compared using two sample $t$ test assuming unequal population variances.

TABLE 8. Average surface roughness for the two fluids at different runs.

\begin{tabular}{|c|c|c|}
\hline RUN & $\begin{array}{c}\text { Av. R } \\
\text { CUTTING FLUID } 1 \\
40 \mathrm{~A}(\mu \mathrm{m})[\mathrm{A}]\end{array}$ & $\begin{array}{c}\text { Av. } \mathrm{R}_{\mathrm{a}} \\
\text { CUTTING FLUID 2 } \\
30 \mathrm{~A}(\mu \mathrm{m})[\mathrm{B}]\end{array}$ \\
\hline 1 & 2.1800 & 2.6675 \\
\hline 2 & 3.0050 & 3.6500 \\
\hline 3 & 1.8200 & 2.2825 \\
\hline 4 & 2.6800 & 2.6600 \\
\hline 5 & 2.5000 & 2.6650 \\
\hline 6 & 3.2025 & 3.5600 \\
\hline 7 & 2.9000 & 3.2650 \\
\hline 8 & 2.4875 & 2.7625 \\
\hline
\end{tabular}

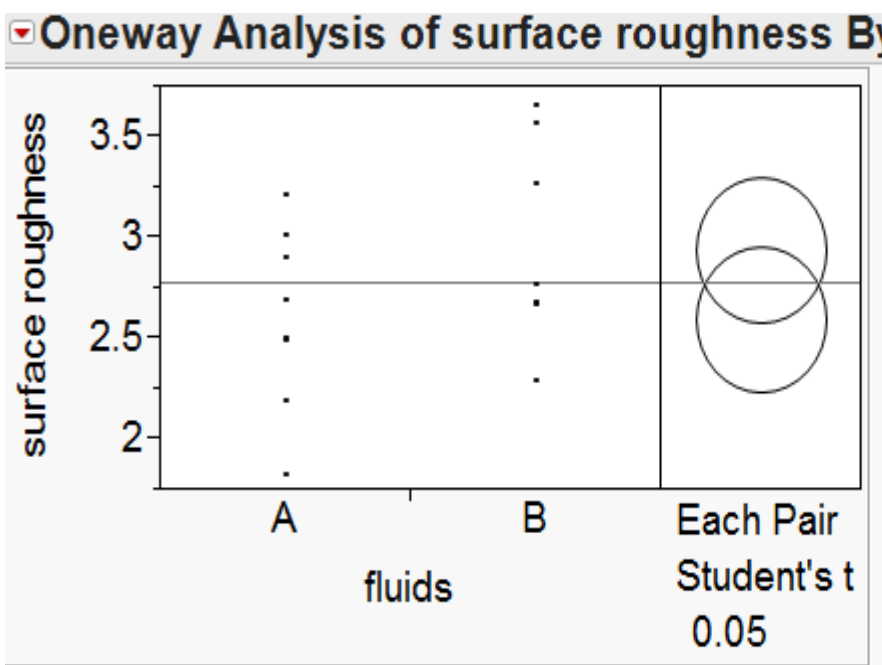

Fig. 5 Shows one way analysis of surface roughness by fluids. 


\section{$\triangle$ Comparing B with A}

\begin{tabular}{|c|c|c|c|c|}
\hline Difference & 0.34219 t Ratio & 1.450402 & & \\
\hline Sto & $0.23593 \mathrm{DF}$ & 14 & & \\
\hline Upp & 0.84820 Prob $>|t|$ & 0.1690 & & \\
\hline Lowe & -0.16382 Prob $>t$ & 0.0845 & 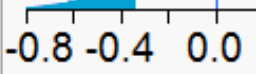 & 0.40 .8 \\
\hline
\end{tabular}

Fig.6 Shows t test comparing fluid A and B on basis of surface roughness.

The $t$ test here shows that there is no significant difference between the cutting fluids in terms of their effect on surface roughness.

Table 9. Average workpiece tool interface temperature for the two fluids at different runs.

\begin{tabular}{|c|c|c|}
\hline RUN & $\begin{array}{c}\text { Av. Temperature } \\
\text { CUTTING FLUID 1 } \\
40 \mathrm{~A}\left({ }^{0} \mathrm{C}\right)[\mathrm{a}]\end{array}$ & $\begin{array}{c}\text { Av. Temperature } \\
\text { CUTTING FLUID 2 } \\
\text { 30 A }\left({ }^{0} \mathrm{C}\right)[\mathrm{b}]\end{array}$ \\
\hline 1 & 25.80 & 25.30 \\
\hline 2 & 25.15 & 24.60 \\
\hline 3 & 24.25 & 25.65 \\
\hline 4 & 26.30 & 28.25 \\
\hline 5 & 25.85 & 25.60 \\
\hline 6 & 26.75 & 25.50 \\
\hline 7 & 27.30 & 26.50 \\
\hline 8 & 27.25 & 27.40 \\
\hline
\end{tabular}

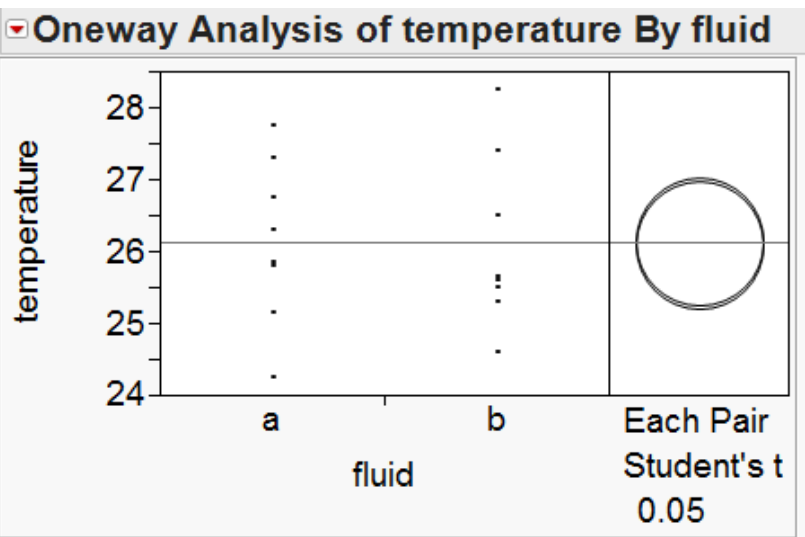

Fig.7 Shows one way analysis of temperature on workpiece tool interface by fluids.

\section{$\triangle$ Comparing b with a}

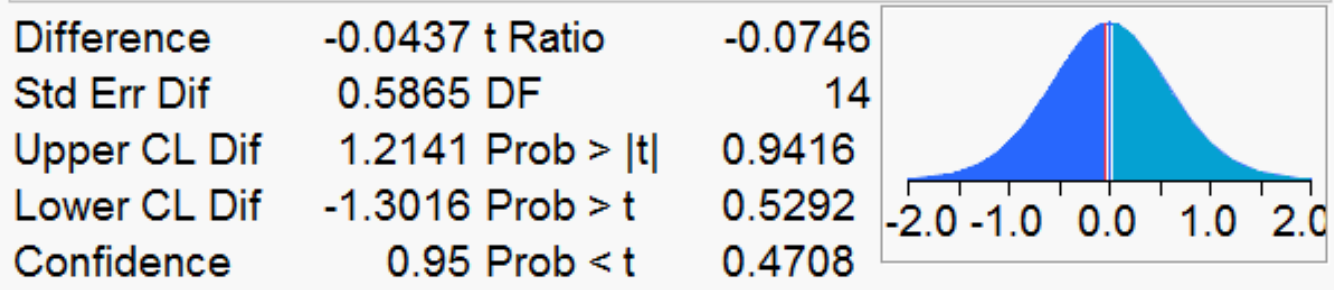

Fig.8 Shows $t$ test comparing fluid $a$ and $b$ on basis of temperature.

The $t$ test here shows that there is no significant difference between the cutting fluids in terms of their effect on temperature during turning. 


\subsubsection{Verification of optimality.}

It was found out by turning operation on levels L1 of speed, feed, concentration and L2 of depth of cut using both cutting fluids, the average surface roughness came out to be $1.91 \mu \mathrm{m}$ slightly more than 1.898938 predicted with the desirability of .995973 .

\section{Conclusion and recommendations}

In this study we utilized latest statistical techniques and design criteria for determining the optimum turning parameters for surface finish.

$>$ Feed rate has significant and the most dominant effect on surface roughness.

$>$ It is found out that surface roughness tends to increase with increase in speed, feed and concentration of cutting fluid but show opposite trend when depth of cut is increased.

$>$ The nuisance factor of cutting fluid was found to have statistically insignificant effect but it helped to make the design more robust.

$>$ The use of custom design method in JMP statistical software helped in reducing the number of experiments from 64 to 16.

$>$ The decrease in cutting fluid concentration improves surface roughness of EN 8.

While this study succeeded in achieving the optimal response utilizing minimum resources and time. This area of research is still wide open as we came to know that the factors like depth of cut are to be explored more as it shows variable trends in many different experiments. Dry, flood and MQL fluid application methods are to be compared on the basis of their effect on surface roughness and tool wear rate.

Acknowledgement - Thanking Guru Nanak Industries, Rajpura and Nirmal oils, Chandigarh for their valuable support and assistance.

\section{References}

[1] S.S Mahapatra, Amar Patnaik, Prabina Ku. Patnaik, Parametric Analysis and Optimization of Cutting Parameters for Turning Operations based on Taguchi Method, Proceedings of the International Conference on Global Manufacturing and Innovation, July 27-29,2006.

[2] M. Anthony Xavior, M. Adithan, Determining the influence of cutting fluids on tool wear and surface roughness during turning of AISI 304 austenic stainless steel, Journal of Materials Processing Technology 209, 2009, 900-909.

[3] M. M. A. Khan, M. A. H. Mithu, N.R. Dhar, Effects of minimum quantity lubrication on turning AISI 9310 alloy steel using vegetable oil based cutting fluid, Journal of Materials Processing Technology 209, 2009, 5573-5583.

[4] L.B Abhang, M. Hameedullah, Modeling and Analysis for Surface roughness in Machining EN-31 steel using Response Surface Methodology, International Journal of Applied Research in Mechanical Engineering, Volume-1, Issue.1, 2011.

[5] Chorng-Jyh Tzeng, Yu-Hsin Lin, Yung-Kuang Yang, Ming-Chang Jeng, Optimization of turning operations with multiple performance characteristics using the Taguchi method and Grey relational analysis, Journal of Materials Processing Technology 209, 2009, 2753-2759.

[6] Rahul Davis, Optimization of Surface Roughness in wet Turning operation of EN24 steel, International Journal of Mechanical and Production Engineering Research and Development (IJMPERD) ISSN 2249-6890, volume 2, Issue 3, 2012, 28-35.

[7] http://en.wikipedia.org/wiki/Speeds and feeds.

[8] http://www.steelexpress.co.uk/engineeringsteel/EN8.html .

[9] W.H. Yang, Y.S Tarng, Design optimization of cutting parameters for turning operations based on the Taguchi method, Journal of Material Processing Technology 84, 1998, 122-129.

[10] J. Kopac, M. Bahor and M. Sokovic, Optimal machining parameters for achieving the desired surface roughness in fine turning of cold pre-formed steel workpieces, International Journal of Machine Tools and Manufacture, 2002,707-716.

[11] J.P. Davim, Design of optimization of cutting parameters for turning metal matrix composites based on orthogonal arrays, , Journal of Material Processing Technology 132, 2003, 340-344.

[12] E. Daniel Kirby, A parameter design study in a turning operation using the Taguchi method, the Technology Interface, 2006.

[13] S. Thamizhmannii, S. Saparudin, S. Hasan, Journal of Achievements in Materials and Manufacturing Engineering, Volume 20, Issues 1-2, 2007.

[14] Nitin Sharma, Shahzad Ahmed, Zahid A. Khan, Arshad Noor Siddiquee, Optimization of cutting parameters for Surface roughness in Turning, International Journal of Advanced Research in Engineering and Technology, Volume 3, Issue 1, 2012, 86-96.

[15] Mahendra Korat, Neeraj Agarwal, Optimization of Different Machining parameters of EN24 alloy steel in CNC Turning by use of Taguchi method, International Journal of Engineering Research and Applications (IJERA) ISSN 2248-9622,Volume 2, Issue 5, 2012,160-664.

[16] Hardeep Singh, Rajesh Khanna, M.P. Garg, Effect of Cutting parameter on MRR and Surface Roughness in Turning EN-8, Current Trends in Engineering Research Vol.1, No.1, 2011.

[17] Didar singh, Mukesh Verma, H. Singh, Experimental Investigation of Surface Roughness and MRR in dry Turning of EN-8 on CNC lathe.

[18] A.E. Diniz, R. Micaroni, Cutting conditions for finish turning process aiming: the use of dry cutting, International Journal of Machine Tools and Manufacture, Volume 42, 2002, 899-904

[19] Rudolf Jacob Freund, Ramon C. Littell, Lee Creighton, Regression using JMP, 2003.

[20] John Sall, Leverage plots for General Linear Hypotheses, The American Statistician, Volume 44, No.4, 1990

[21] http://www.jmp.com/support/help/Leverage_Plot_Details.shtml. 